\title{
Etnobotânica de plantas medicinais em duas comunidades do município de Picuí, Paraíba, Brasil
}

\author{
COSTA, J.C. ${ }^{* *}$; MARINHO, M.G.V. ${ }^{2}$ \\ 1Universidade Federal de Campina Grande, Centro de Saúde e Tecnologia Rural, Programa de Pós-Graduação \\ em Ciências Florestais e Ambientais, ${ }^{2}$ Unidade Acadêmica de Ciências Biológicas, Rodovia Patos/Teixeira, Bairro \\ Jatobá, CEP: 58704-330, Patos-PB, Brasil. *Autor para correspondência: jeanbarros1@hotmail.com
}

\begin{abstract}
RESUMO: O presente trabalho realizou um levantamento etnobotânico sobre a utilização de plantas medicinais no município de Picuí, Seridó Oriental, Estado da Paraíba, Brasil. Foi analisada uma área urbana (bairro monte santo) e uma rural (sítio massapê). As informações etnobotânicas foram obtidas através de formulários semiestruturados, contendo características socioeconômicas dos entrevistados, características das plantas e seus usos terapêuticos. Para a entrevista foi selecionado o adulto responsável pela residência, "chefe de família", e utilizou-se a técnica da "bola de neve". Foram citadas 37 famílias botânicas, 59 gêneros e 64 espécies. As espécies mais citadas foram Vernonia condensata Baker e Chenopodium ambrosioides L. e a família mais indicada foi Fabaceae. O hábito predominante foi o herbáceo, seguido do arbóreo; as partes da planta mais utilizadas foram as folhas e as cascas do caule; os principais modos de preparo dos remédios foram os chás e a água e/ou sumo. A planta com maior CUPC foi Vernonia condensata Baker (41,67\%), sendo também uma das plantas com maior FRt junto a Chenopodium ambrosioides L., ambas com 19,6\%. Esses resultados demonstraram que as populações estudadas ainda usam plantas medicinais com frequência, entretanto, a maioria das plantas utilizadas não é nativa da caatinga.
\end{abstract}

Palavras-chave: Etnobotânica. Plantas medicinais. Paraíba.

\begin{abstract}
Ethnobotanic of medicinal plants in two communities in the municipality of Picuí, Paraíba, Brazil. This study conducted an ethnobotanical survey on the use of medicinal plants in the municipality of Picuí, Seridó of Paraíba, Brazil. An urban area (neighborhood monte santo) and a rural area (massapê farm) were analysed. The ethnobotanical information was obtained through semi-structured questionary containing socioeconomic characteristics of the respondents, characteristics of plants and their therapeutic uses. We selected an adult which was the responsible adult of the residence "householder" for the interview and used the technique of "snowball". 37 plant families, 59 genera and 64 species were cited. The species most frequently cited were Vernonia condensata Baker and Chenopodium ambrosioides $L$. and the most mentioned family was Fabaceae. The predominant habit was the herbaceous, followed by woody, the parts of the plant which were most used are the leaves and bark of the stem, the main modes of preparation of the medicines were showers and water and / or lushness. The plant with the highest CUPc was Vernonia condensata Baker (41.67\%), and it was also one of the plants with greatest FRt along with Chenopodium ambrosioides L., both with $19.6 \%$. These results demonstrated that the studied populations still use medicinal plants often, however, most of the plants used is not native to the caatinga.
\end{abstract}

Keywords: Ethnobotany. Medicinal plants. Paraíba.

\section{INTRODUÇÃO}

A maior parte da região Nordeste do Brasil que apresenta clima semiárido é coberta por uma vegetação denominada caatinga, cujos recursos florestais têm sido objeto de intensa utilização para satisfazer as necessidades humanas dessa região semiárida. Na realidade, os recursos florestais da 
região servem para diversos fins, estando presentes na alimentação, vestuário, lazer, habitação e saúde das populações (Gariglio et al., 2010).

A etnobotânica é uma ciência muito importante para o estudo da caatinga e seus recursos florestais, já que esse ramo do conhecimento analisa os saberes de populações tradicionais em relação à utilização de plantas. Sabe-se que as populações tradicionais possuem uma interação muito forte com o meio a sua volta e, portanto, são detentoras de conhecimentos milenares que são repassados de geração para geração. Entretanto, a interferência de fatores externos à dinâmica social dessas populações (maior acesso à medicina ocidental e a instituições de saúde, conversão religiosa, aumento da educação formal, etc.) pode está levando a uma perda desses conhecimentos, principalmente aqueles relacionados com a fitoterapia (Almeida et al., 2009).

Segundo Palmer (2004) a incorporação de novos conhecimentos em uma comunidade tradicional pode ser considerada um fato negativo, pois pode causar a perda de saberes tradicionais em detrimento da inserção de novas informações. Contudo, outros pesquisadores acreditam que estes fatos não causam a perda dos conhecimentos, mas sim agregam novas informações ao conhecimento tradicional preexistente (Bennett \& Prance, 2000).

$\mathrm{Na}$ Paraíba, o uso de plantas medicinais com fins terapêuticos é bastante comum, principalmente no meio rural e urbano de baixo poder aquisitivo (Agra \& Silva, 1993). Nesse sentido, este trabalho propôs a análise dos conhecimentos etnobotânicos em uma comunidade rural e urbana do município de Picuí, Seridó Oriental Paraibano.

\section{MATERIAL E MÉTODO}

A pesquisa foi realizada no município de Picuí, Mesorregião da Borborema e Microrregião do Seridó Oriental da Paraíba. O município possui uma área de $661.657 \mathrm{Km}^{2}$, população estimada de 18.634 pessoas e está situado no domínio da caatinga entre os paralelos $6.55^{\circ} \mathrm{S}$ e $36.34^{\circ}$ W (Figura 1). De acordo com a classificação de Köppen a região apresenta clima do tipo (Bsh), árido, muito seco e com chuvas escassas. Os solos são predominantemente jovens, destacando-se os solos Litólicos, Regossolos e Brunos Não Cálcicos (lbge, 2010).

A pesquisa foi realizada em duas comunidades do município e para a seleção das mesmas observou-se os seguintes critérios: grande utilização de plantas medicinais na comunidade, cultivo de ervas medicinais em casa e presença de curandeiras/curandeiros e benzedeiras/benzedeiros na comunidade. Partindo deste pressuposto, as localidades escolhidas para o estudo foram o bairro monte santo (zona urbana: $06^{\circ} 30^{\prime} 38,0^{\prime \prime} \mathrm{S}-36^{\circ} 20^{\prime}$ $49,0^{\prime \prime}$ W) e o sítio massapê (zona rural: $06^{\circ} 37^{\prime} 35$, $4 " \mathrm{~S}$ - 36² 21' 26, 4" W).

A coleta de dados ocorreu entre janeiro e dezembro de 2012, através de entrevistas estruturadas e semiestruturadas. Foram aplicados formulários socioeconômicos e roteiros para a coleta de dados sobre plantas medicinais (Albuquerque \& Lucena, 2004). A seleção das residências pesquisadas foi baseada na técnica da "bola de neve" (Bailey, 1994) e no conceito de "chefe de família", em que apenas o adulto responsável pela residência e que detém o maior conhecimento sobre o assunto é entrevistado (Da Silva, 2007; Massaroto, 2009). Assim, na zona urbana foram entrevistadas

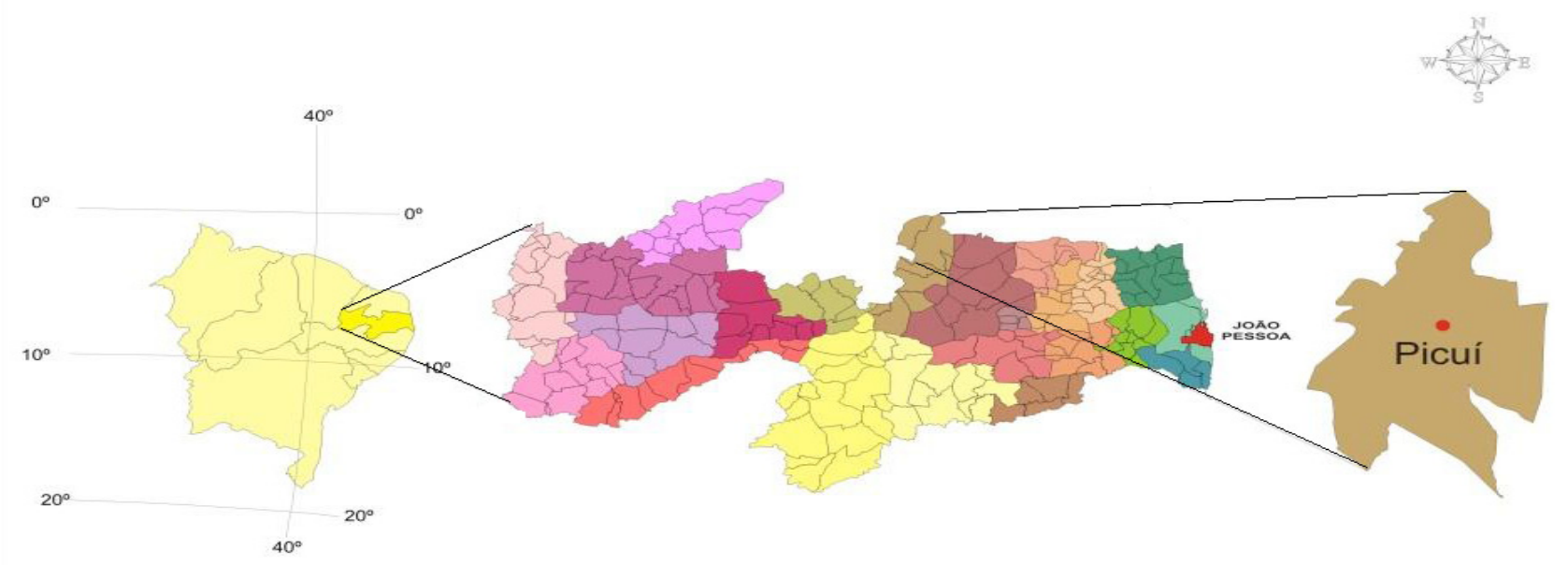

PROJEÇÃO UTM - SAD69

FONTE DA BASE CARTOGRÁFICA : IBGE 2009

FIGURA 1. Localização da área de estudo (fonte: francisco et al., 2011 modificado).

Rev. Bras. PI. Med., Campinas, v.18, n.1, p.125-134, 2016. 
quinze informantes e na zona rural catorze.

Todas as entrevistas foram fotografadas e gravadas para que nenhum dado fosse perdido e muitos trechos das conversas foram transcritos. Os entrevistados ficaram a vontade para relatar suas experiências e foram acompanhados nos quintais e na própria mata para a coleta das plantas citadas. O material coletado foi depositado no Herbário da Universidade Federal de Campina Grande, Centro de Saúde e Tecnologia Rural - Campus Patos - PB, sob os números de coletas CSTR-3791 a CSTR3854.

Os dados obtidos nas entrevistas foram analisados pelos seguintes critérios: frequência do hábito de vida: calculou-se a porcentagem relativa do hábito de vida de cada espécie citada; frequência da parte utilizada: calculou-se o número total de vezes que determinada parte vegetal foi citada para o preparo dos remédios; frequência do modo de preparo dos remédios: calculou-se o número total de vezes que determinada preparação caseira foi citada; frequência de citação da família botânica: calculou-se o número total de espécies da mesma família, citadas por diferentes informantes; frequência de citação da espécie: calculou-se o número de citações da mesma espécie por diferentes informantes (Prance et al., 1987).

A partir dos dados obtidos também foram realizadas as seguintes análises qualitativas: índice de concordância de uso principal (CUP): demonstra a importância relativa das plantas utilizadas quanto ao número de entrevistados que as citaram e a concordância dos usos citados (Equação 1). Para este cálculo, foram consideradas apenas as plantas citadas por cinco ou mais entrevistados (Amorozo \& Gely, 1988). (1) CUP = (ICUP/ICUE) $\times$ 100, onde: CUP = índice de concordância de uso principal; ICUP = número de entrevistados citando o uso principal da espécie; ICUE = número total de entrevistados citando uso da espécie. Calculou-se o fator de correção (FC) para cada espécie (Equação 2). (2) $F C=I C U E / I C E M C$, onde: $F C=$ fator de correção para cada espécie; ICUE = número total de entrevistados citando uso da espécie; ICEMC = número de citações da espécie mais indicada. Em seguida obteve-se o índice de concordância de uso principal corrigido (CUPc): que permite a extração de valores de importância relacionados à espécie mais citada pela comunidade (Equação 3). (3) CUPc = CUP $\times$ FC, onde: CUPC = índice de concordância de uso corrigido; CUP = índice de concordância de uso principal; FC = fator de correção para cada espécie.

A frequência relativa das plantas medicinais foi calculada no Programa Microsoft Excel 2010, com base em Rodal et al. (1992). Essa análise levou em consideração todas as plantas medicinais citadas nas duas áreas de estudo (Equações 4 e 5). (4)
$\mathrm{FA} t=100 \times(\mathrm{NUA} / \mathrm{NUT})(5) \mathrm{FR} t=100 \times(\mathrm{FA} t / \mathrm{FT})$ Onde: $\mathrm{FA} t=$ frequência absoluta do táxon $t(\%), \mathrm{NUA}$ = número de unidades amostrais (questionários) com ocorrência do táxon $t$, NUT = número total de unidades amostrais (questionários aplicados), FRt = frequência relativa do táxon $t(\%)$ e $\mathrm{FT}=$ frequência total da amostra (somatório de todas as citações de plantas). Apenas as plantas que apresentaram frequência relativa $\geq 5 \%$ foram consideradas para fins de discussão.

\section{RESULTADOS E DISCUSSÃO Uso de plantas medicinais no bairro monte santo}

Em quinze entrevistas realizadas foram identificadas quarenta e oito espécies de plantas medicinais, sendo as mais citadas Vernonia condensata Baker (boldo) e Lippia alba (Mill.) N.E. Br. ex Britton \& P. Wilson (erva cidreira). A família botânica mais citada nessa comunidade foi Asteraceae. Assim, podemos perceber que as plantas mais citadas na zona urbana não são nativas da caatinga.

Em relação aos hábitos das plantas citadas, observou-se que a maioria apresentava porte herbáceo, seguido das plantas de porte arbóreo (Figura 2).

Verificou-se que a folha é a parte vegetal mais usada na fabricação dos remédios, seguida das cascas do caule (Figura 3).

A maioria dos informantes afirmou que utiliza os chás como principal modo de preparo dos remédios, seguido do uso da água ou sumo da planta e do lambedor ou xarope (Figura 4). Em todo o mundo é comum o uso de chás, entretanto, na maioria das vezes, os chás são utilizados como forma de alimento e não como medicamento. Assim, o uso de chás na área estudada pode ser um indício de que o conhecimento etnobotânico desta região está sendo influenciado por fatores externos a comunidade. Marinho (2006) realizou um estudo etnobotânico em duas comunidades do Sertão da Paraíba e verificou que o chá também era a principal forma de preparo dos medicamentos caseiros.

Para as análises qualitativas das plantas mencionadas pelos informantes do bairro monte santo, foram listadas 7 (sete) espécies (Tabela 1).

Observou-se que a planta que apresentou o maior CUPc foi Vernonia condensata Baker. As espécies Eucalyptus globulus Labill e Chamomilla recutita (L.) Rauschert apresentaram alto CUP, entretanto, quando se aplicou o FC estes valores baixaram consideravelmente. É importante ressaltar que nenhuma espécie da comunidade apresentou CUPc maior que $50 \%$. 


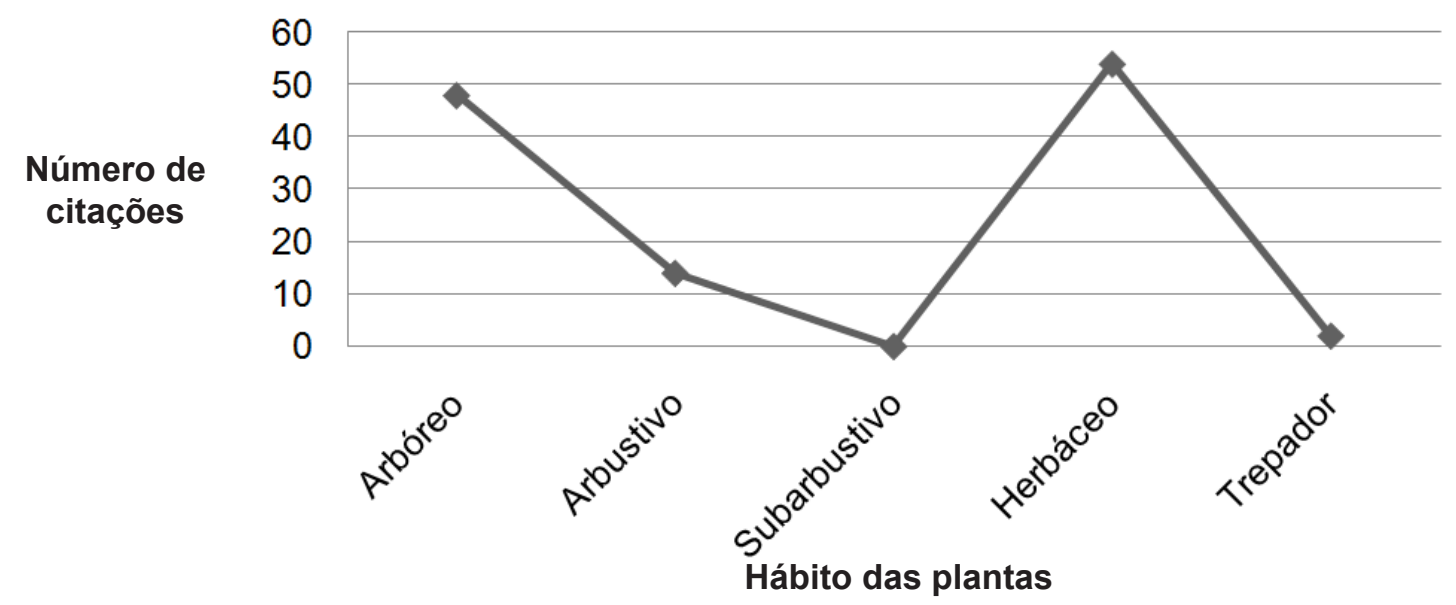

FIGURA 2. Hábitos das plantas utilizadas como remédios pelos informantes da zona urbana.

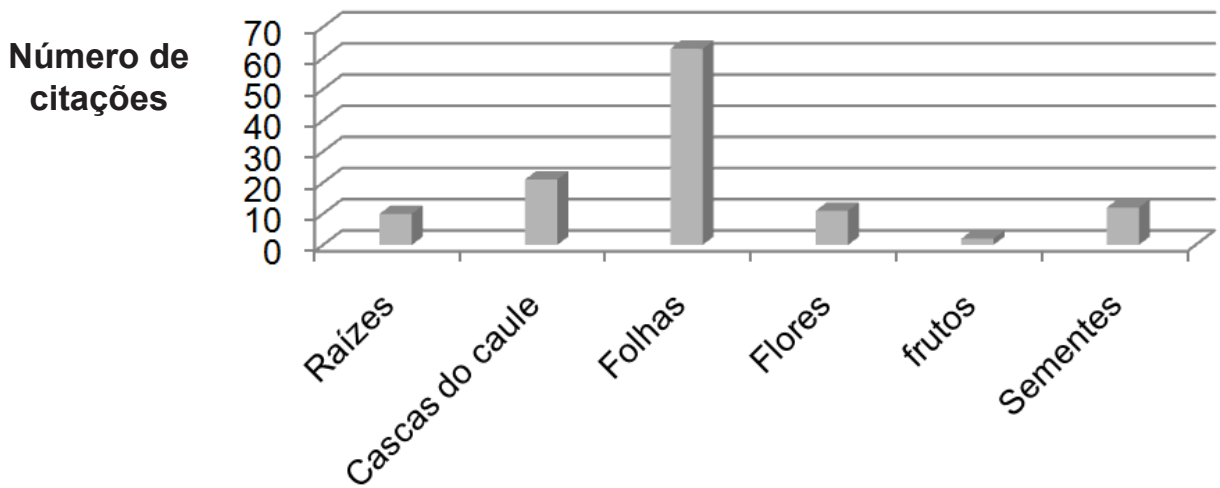

Partes das plantas

FIGURA 3. Partes das plantas utilizadas como remédios pelos informantes da zona urbana.

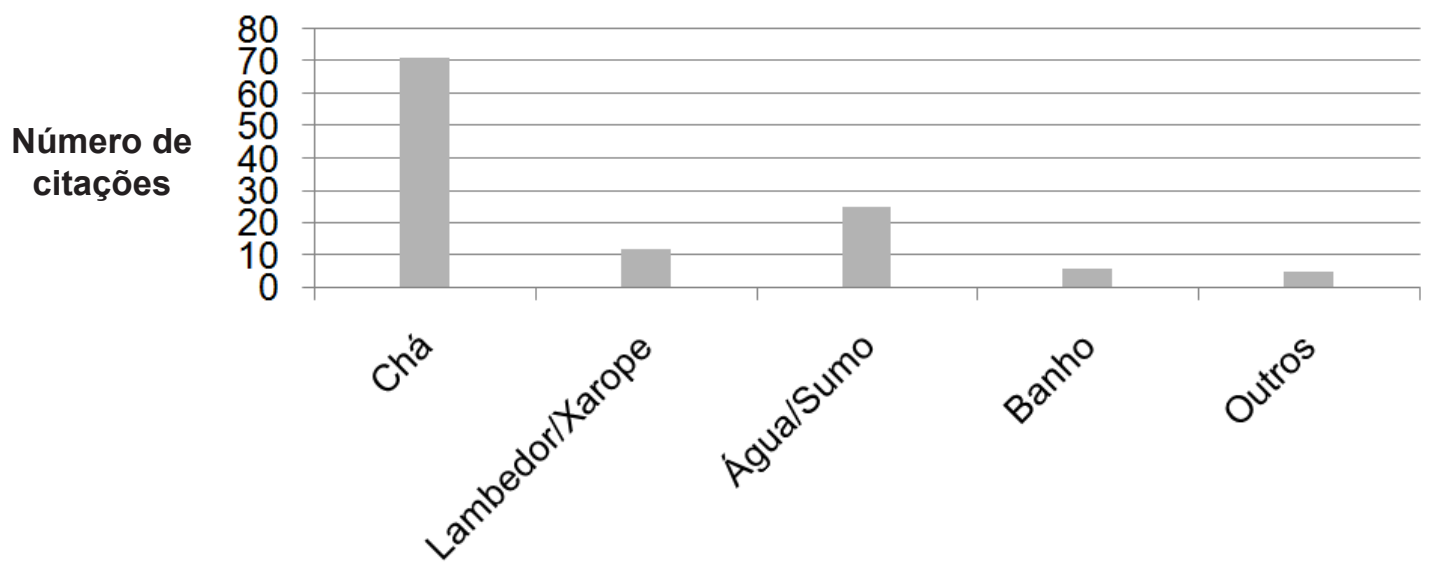

Modos de preparo dos remédios

FIGURA 4. Modos de preparo dos remédios caseiros pelos informantes da zona urbana. 
TABELA 1. Análises qualitativas na zona urbana.

\begin{tabular}{lllccccc}
\hline Nome Científico & Nome Popular & UP & ICUE & ICUP & CUP & FC & CUPc \\
\hline Vernonia condensata Baker & Boldo & Má digestão & 12 & 5 & 41,67 & 1 & 41,67 \\
Chenopodium ambrosioides L. & Mastruz & Gastrite e gripe & 6 & 3 & 50 & 0,5 & 25 \\
Mentha x villosa Huds. & Hortelã miúda & Amebíase e vermes & 6 & 2 & 33,33 & 0,5 & 16,67 \\
Eucalyptus globulus Labill. & Eucalipto & Gripe e febre & 5 & 3 & 60 & 0,42 & 25,2 \\
Chamomilla recutita (L.) Rauschert & Camomila & Calmante & 6 & 3 & 50 & 0,5 & 25 \\
Lippia alba (Mill.) N.E. Br. & Erva cidreira & Má digestão & 8 & 3 & 37,5 & 0,67 & 25,12 \\
ex Britton \& P. Wilson & & e cólicas intestinais & & & & & \\
Camellia sinensis (L.) Kuntze & Chá preto & Febre & 5 & 2 & 40 & 0,42 & 16,8 \\
\hline
\end{tabular}

Uso de plantas medicinais no sítio massapê

Em catorze entrevistas realizadas foram identificadas quarenta e duas espécies de plantas medicinais, sendo as mais citadas Chenopodium ambrosioides L. (mastruz) e Plectranthus amboinicus (Lour.) Spreng. (hortelã da folha grossa). A família mais citada nesta comunidade foi Fabaceae. Souza \& Felfili (2006) realizaram uma pesquisa etnobotânica na região de Alto Paraíso de GoiásGO e afirmaram que Chenopodium ambrosioides L. também era uma das espécies mais utilizadas pelos indivíduos entrevistados. Em um estudo etnobotânico realizado no Sítio Nazaré, município de Milagres, $C E$, a família mais representativa para fins medicinais também foi a Fabaceae (Da Silva, 2012). Portanto, as plantas mais citadas na zona rural do município também não são nativas da caatinga.

Em relação aos hábitos das plantas observou-se que a maioria apresentava porte herbáceo, seguido do porte arbóreo (Figura 5).

Em relação às partes das plantas utilizadas na fabricação de remédios, verificou-se que a parte mais utilizada era a folha, seguida das cascas do caule (Figura 6).

Assim como na área urbana a maioria dos informantes afirmou que utiliza chás como principal modo de preparo dos remédios, seguido de água ou sumo e do lambedor ou xarope (Figura 7). Resultados análogos também foram encontrados por Almeida et al. (2009) em um levantamento etnobotânico realizado na cidade de Viçosa-MG.

Apenas duas espécies foram selecionadas para as análises qualitativas no sítio massapê (Tabela 2).

Observou-se que Plectranthus amboinicus (Lour.) Spreng. obteve um CUP maior que Chenopodium ambrosioides L.. Entretanto, quando se utilizou o FC a planta Chenopodium ambrosioides L. apresentou um CUPc maior. Esses dados demonstraram índices muito baixos de CUPc quando comparado com outros trabalhos da área (Massaroto, 2009; Da Silva, 2007).

\section{CONCLUSÃO}

Analisando a área urbana e a rural simultaneamente, observamos que foram citadas trinta e sete famílias botânicas, cinquenta e nove gêneros e sessenta e quatro espécies (Tabela 3). As espécies mais citadas foram Vernonia condensata Baker e Chenopodium ambrosioides L. e a família mais indicada foi a Fabaceae. É importante ressaltar

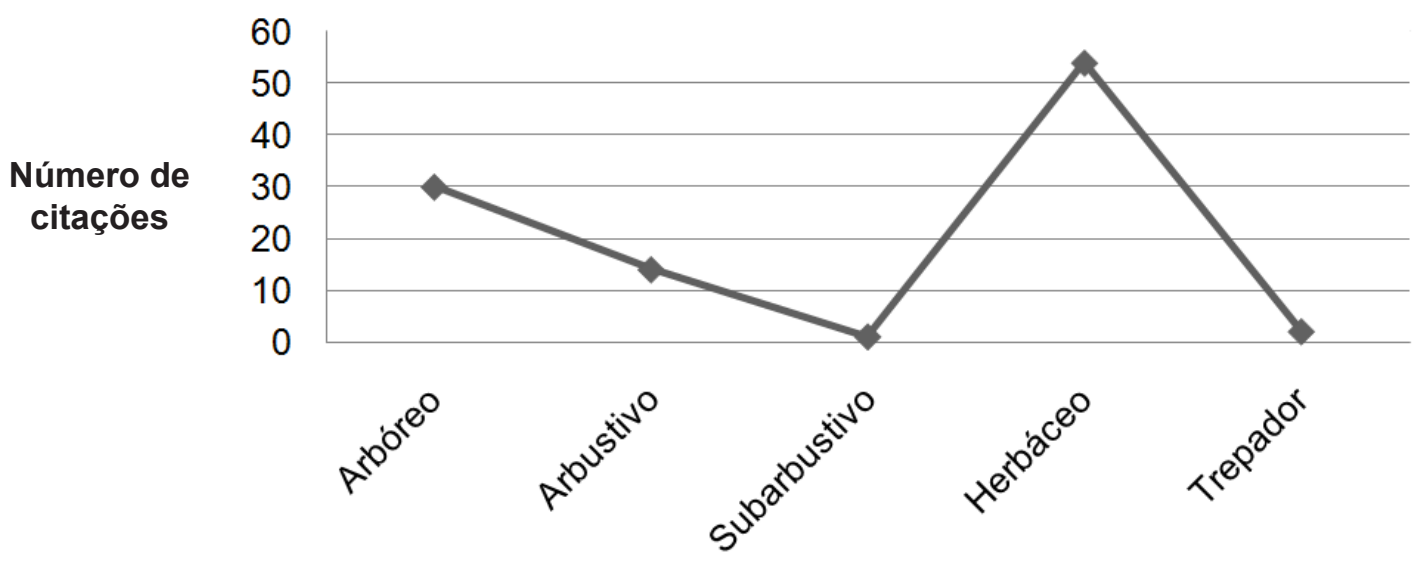

Hábito das plantas

FIGURA 5. Hábitos das plantas utilizadas como remédios pelos informantes da zona rural.

Rev. Bras. PI. Med., Campinas, v.18, n.1, p.125-134, 2016. 


\section{Número de} citações

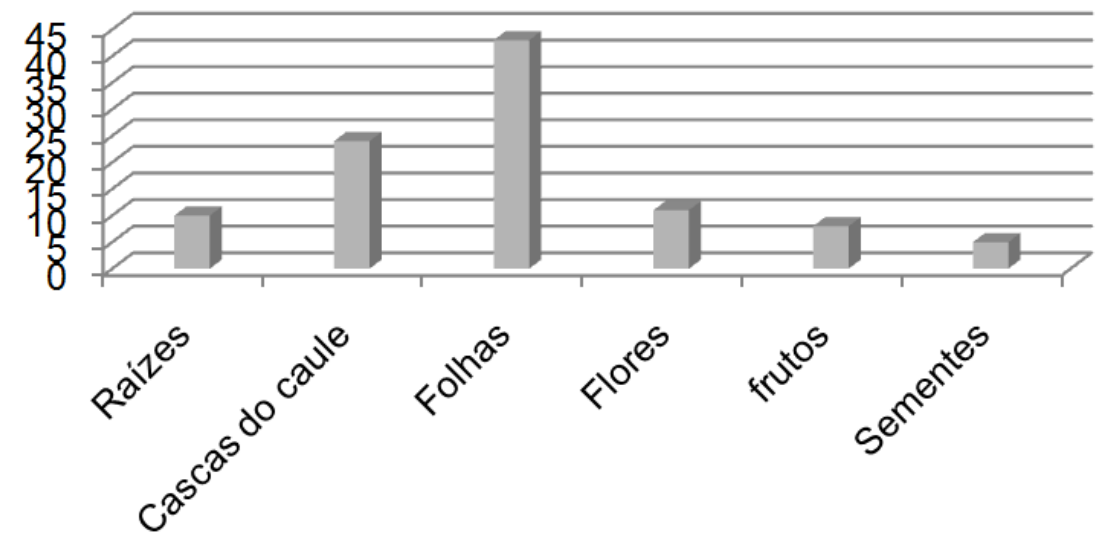

Partes das plantas

FIGURA 6. Partes das plantas utilizadas como remédios pelos informantes da zona rural.

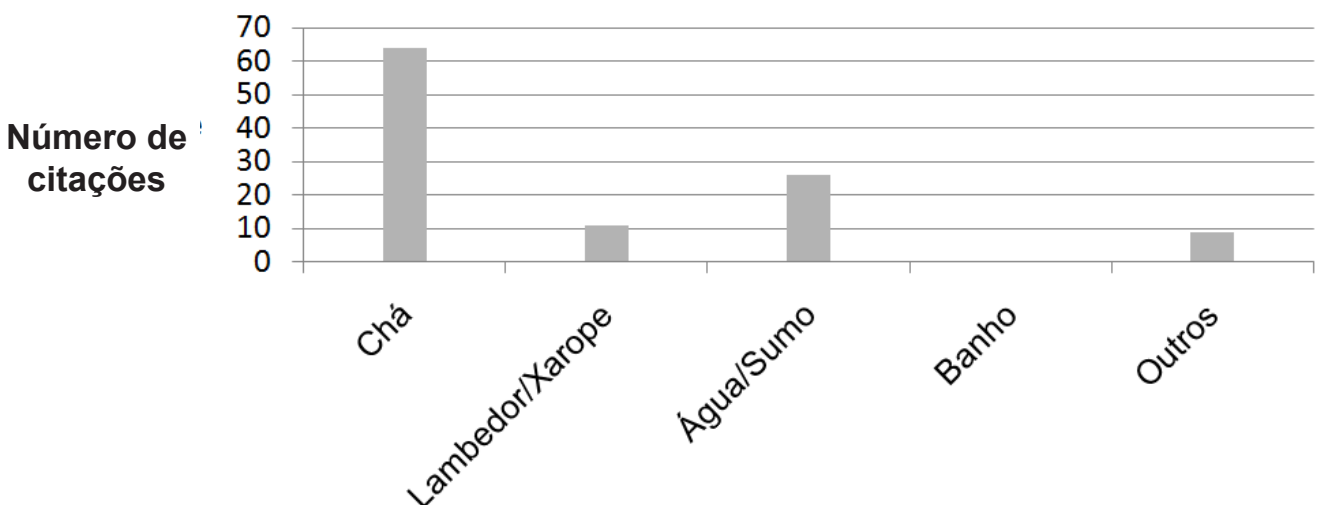

Modos de preparo dos remédios

FIGURA 7. Modos de preparo dos remédios caseiros pelos informantes da zona rural

TABELA 2. Análises qualitativas na zona rural.

\begin{tabular}{llllllll}
\hline Nome Científico & Nome Popular & UP & ICUE & ICUP & CUP & FC & CUPc \\
\hline Chenopodium ambrosioides L. & Mastruz & Gastrite & 6 & 2 & 33,33 & 1 & 33,33 \\
Plectranthus amboinicus (Lour.) Spreng. & Hortelã grossa & Gripe & 5 & 2 & 40 & 0,83 & 33,2 \\
\hline
\end{tabular}

TABELA 3. Relação de espécies medicinais utilizadas pelas comunidades do município de picuí-pb. Convenção: ni/pi = número de indicações por planta pelos informantes

\begin{tabular}{|c|c|c|c|c|c|c|c|}
\hline Família & Nome Científico & Nome popular & $\begin{array}{l}\text { Parte(s) } \\
\text { usada(s) }\end{array}$ & $\begin{array}{c}\text { Forma(s) de } \\
\text { uso(s) }\end{array}$ & $\begin{array}{c}\text { Indicação(ões) } \\
\text { terapêutica(s) }\end{array}$ & $\begin{array}{l}\mathrm{NI} / \\
\mathrm{PI}\end{array}$ & $\begin{array}{c}\text { Frequência } \\
\text { Relativa } \\
(\geq 5 \%)\end{array}$ \\
\hline Adoxaceae & $\begin{array}{c}\text { Sambucus australis } \\
\text { Cham. \& Schltdl. }\end{array}$ & Sabugueiro & Flor & Chá & $\begin{array}{c}\text { Febre, sarampo, } \\
\text { gripe }\end{array}$ & 4 & - \\
\hline Amaranthaceae & $\begin{array}{l}\text { Chenopodium } \\
\text { ambrosioides L. }\end{array}$ & Mastruz & Folha & $\begin{array}{c}\text { Chá, lambedor, } \\
\text { sumo }\end{array}$ & $\begin{array}{l}\text { Gripe, gastrite, } \\
\text { úlcera, ameba }\end{array}$ & 12 & $19,6 \%$ \\
\hline $\begin{array}{l}\text { Amaryllidaceae } \\
\text { Allium cepa L. }\end{array}$ & & Cebola branca & Caule (bulbo) & Lambedor & Gripe & 2 & - \\
\hline Amaryllidaceae & Allium sativum $\mathrm{L}$. & Alho & Caule (bulbo) & Chá & $\begin{array}{c}\text { Tosse, gripe, vermes, } \\
\text { dor de dente, febre }\end{array}$ & 4 & - \\
\hline
\end{tabular}


TABELA 3. Relação de espécies medicinais utilizadas pelas comunidades do município de picuí-pb. Convenção: ni/pi = número de indicações por planta pelos informantes.

\begin{tabular}{|c|c|c|c|c|c|c|c|}
\hline Anacardiaceae & $\begin{array}{c}\text { Anacardium } \\
\text { occidentale L. }\end{array}$ & Cajueiro & $\begin{array}{l}\text { Casca do } \\
\text { caule }\end{array}$ & Água, chá & $\begin{array}{l}\text { Ferimentos, } \\
\text { inflamações }\end{array}$ & 5 & $8,1 \%$ \\
\hline Anacardiaceae & $\begin{array}{c}\text { Myracrodruon } \\
\text { urundeuva Allemão }\end{array}$ & Aroeira & $\begin{array}{c}\text { Casca do } \\
\text { caule }\end{array}$ & Água & Inflamações & 2 & - \\
\hline Annonaceae & Annona muricata L. & Graviola & Folha & Chá & $\begin{array}{c}\text { Colesterol alto, dor } \\
\text { de coluna }\end{array}$ & 1 & - \\
\hline Apiaceae & $\begin{array}{c}\text { Anethum graviolens } \\
\text { L. }\end{array}$ & Endril & Semente & Chá & Tosse, dor de barriga & 2 & - \\
\hline Apiaceae & Pimpinella anisum L. & Erva doce & Semente & Chá & Calmante & 2 & - \\
\hline Asteraceae & $\begin{array}{l}\text { Baccharis trimera } \\
\text { (Less.) DC. }\end{array}$ & Carqueja & Folha & Chá & $\begin{array}{c}\text { Colesterol alto, } \\
\text { obesidade, doenças } \\
\text { do estômago } \\
\end{array}$ & 1 & - \\
\hline Asteraceae & $\begin{array}{c}\text { Chamomilla recutita } \\
\text { (L.) Rauschert }\end{array}$ & Camomila & Flor & Chá, banho & $\begin{array}{c}\text { Calmante, } \\
\text { hipertensão, estresse }\end{array}$ & 10 & $16,3 \%$ \\
\hline Asteraceae & $\begin{array}{c}\text { Egletes viscosa (L.) } \\
\text { Less. }\end{array}$ & Macela & Semente, flor & Chá & $\begin{array}{c}\text { Vermes, intestino } \\
\text { preso }\end{array}$ & 5 & $8,1 \%$ \\
\hline Asteraceae & Helianthus annuus L. & Girassol & Semente & Chá & Trombose & 1 & - \\
\hline Asteraceae & $\begin{array}{c}\text { Vernonia condensata } \\
\text { Baker }\end{array}$ & Boldo & Folha & Chá & $\begin{array}{c}\text { Barriga inchada, } \\
\text { gases, doenças do } \\
\text { fígado e do estômago }\end{array}$ & 12 & $19,6 \%$ \\
\hline Boraginaceae & $\begin{array}{c}\text { Heliotropium } \\
\text { elongatum var. } \\
\text { burchellii I.M. Johnst. }\end{array}$ & Fedegoso & Folha, raiz & Chá & $\begin{array}{c}\text { Ferimentos, } \\
\text { bronquite, problemas } \\
\text { pós-parto }\end{array}$ & 6 & $9,8 \%$ \\
\hline Boraginaceae & $\begin{array}{c}\text { Symphytum officinale } \\
\text { L. }\end{array}$ & Confrei & Folha & Lambedor & Inflamações & 2 & - \\
\hline Brassicaceae & $\begin{array}{c}\text { Nasturtium officinale } \\
\text { W.T. Ailton }\end{array}$ & $\begin{array}{l}\text { Agrião de } \\
\text { remédio }\end{array}$ & Semente & Chá, lambedor & $\begin{array}{c}\text { Dor de garganta, } \\
\text { anemia }\end{array}$ & 4 & - \\
\hline Cactaceae & $\begin{array}{c}\text { Melocactus zehntneri } \\
\text { (Britton \& Rose) } \\
\text { Luetzelb. }\end{array}$ & Coroa de frade & Raiz & Sumo & Tosse & 2 & - \\
\hline Cactaceae & $\begin{array}{c}\text { Opuntia } \\
\text { cochenillifera } \\
\text { (L.) Mill. }\end{array}$ & Palma & Raiz & Chá & Tosse, bronquite & 2 & - \\
\hline Celastraceae & $\begin{array}{c}\text { Maytenus officinalis } \\
\text { Mabb. }\end{array}$ & $\begin{array}{c}\text { Espinheira } \\
\text { santa }\end{array}$ & Folha & Chá & Gastrite & 1 & - \\
\hline Cleomaceae & $\begin{array}{c}\text { Tarenaya spinosa } \\
\text { (Jacq.) Raf. }\end{array}$ & Mussambê & Flor, raiz & Chá, lambedor & Gripe, inflamações & 1 & - \\
\hline Crassulaceae & $\begin{array}{c}\text { Bryophyllum } \\
\text { pinnatum (Lam.) } \\
\text { Oken }\end{array}$ & Corama & Folha & Lambedor & Inflamação, infecções & 2 & - \\
\hline Cucurbitaceae & $\begin{array}{c}\text { Apodanthera } \\
\text { congestiflora Cogn. }\end{array}$ & $\begin{array}{c}\text { Cabeça de } \\
\text { nego }\end{array}$ & Raiz & Lambedor & Dores gerais & 2 & - \\
\hline Cucurbitaceae & $\begin{array}{c}\text { Luffa operculata (L.) } \\
\text { Cogn. }\end{array}$ & Cabacinha & Fruto & $\begin{array}{c}\text { Infusão } \\
\text { (inalação do } \\
\text { vapor) } \\
\end{array}$ & Sinusite & 1 & - \\
\hline Euphorbiaceae & $\begin{array}{c}\text { Croton blanchetianus } \\
\text { Baill. }\end{array}$ & Marmeleiro & $\begin{array}{c}\text { Casca do } \\
\text { caule }\end{array}$ & Sumo & Dor de barriga & 2 & - \\
\hline Euphorbiaceae & $\begin{array}{c}\text { Croton } \\
\text { heliotropiifolius Kunth }\end{array}$ & Velame & Raiz & Chá & Tosse & 3 & - \\
\hline Euphorbiaceae & $\begin{array}{l}\text { Croton nepetifolius } \\
\text { Baill. }\end{array}$ & $\begin{array}{l}\text { Marmeleiro } \\
\text { branco }\end{array}$ & $\begin{array}{l}\text { Casca do } \\
\text { caule }\end{array}$ & Pó & Hemorragias & 1 & - \\
\hline
\end{tabular}


TABELA 3. Relação de espécies medicinais utilizadas pelas comunidades do município de picuí-pb. Convenção: ni/pi = número de indicações por planta pelos informantes.

\begin{tabular}{|c|c|c|c|c|c|c|c|}
\hline Fabaceae & $\begin{array}{l}\text { Amburana cearensis } \\
\text { (Allemão) A.C. Sm. }\end{array}$ & $\begin{array}{c}\text { Cumarú, } \\
\text { imburana de } \\
\text { cheiro }\end{array}$ & $\begin{array}{l}\text { Casca do } \\
\text { caule, folha, } \\
\text { semente }\end{array}$ & $\begin{array}{l}\text { Água, lambedor, } \\
\text { banho, chá }\end{array}$ & $\begin{array}{c}\text { Sinusite, trombose, } \\
\text { dores }\end{array}$ & 7 & $11,4 \%$ \\
\hline Fabaceae & $\begin{array}{c}\text { Anadenanthera } \\
\text { colubrina (Vell.) } \\
\text { Brenan }\end{array}$ & Angico & $\begin{array}{l}\text { Casca do } \\
\text { caule }\end{array}$ & Água, lambedor & Dores musculares & 2 & - \\
\hline Fabaceae & $\begin{array}{c}\text { Bauhinia cheilantha } \\
\text { (Bong.) Steud. }\end{array}$ & Mororó & $\begin{array}{c}\text { Casca do } \\
\text { caule }\end{array}$ & Água & $\begin{array}{c}\text { Diabetes, dor de } \\
\text { coluna, colesterol alto }\end{array}$ & 3 & - \\
\hline Fabaceae & $\begin{array}{l}\text { Bowdichia virgilioides } \\
\text { Kunth }\end{array}$ & Sucupira & Semente & Infusão, água & $\begin{array}{l}\text { Sinusite, dor de } \\
\text { coluna, dor de } \\
\text { garganta }\end{array}$ & 2 & - \\
\hline Fabaceae & $\begin{array}{c}\text { Hymenaea courbaril } \\
\text { var. villosa Y.T. Lee \& } \\
\text { Andrade-Lima }\end{array}$ & Jatobá & $\begin{array}{l}\text { Casca do } \\
\text { caule, fruto }\end{array}$ & $\begin{array}{l}\text { Lambedor, } \\
\text { água, } \\
\text { Chá }\end{array}$ & $\begin{array}{c}\text { Anemia, infecção } \\
\text { urinária }\end{array}$ & 5 & $8,1 \%$ \\
\hline Fabaceae & $\begin{array}{c}\text { Mimosa tenuiflora } \\
\text { (Willd.) Poir. }\end{array}$ & Jurema preta & $\begin{array}{c}\text { Casca do } \\
\text { caule }\end{array}$ & Pó & Ferimentos & 2 & - \\
\hline Fabaceae & $\begin{array}{c}\text { Poincianella } \\
\text { pyramidalis (Tul.) } \\
\text { L.P. Queiroz }\end{array}$ & Catingueira & Flor & Chá & Tosse, bronquite & 1 & - \\
\hline Fabaceae & $\begin{array}{c}\text { Senna obtusifolia (L.) } \\
\text { H.S. Irwin \& } \\
\text { Barneby }\end{array}$ & Mata pasto & Raiz & Chá & Dor de barriga & 1 & - \\
\hline Lamiaceae & $\begin{array}{c}\text { Mentha } x \text { villosa } \\
\text { Huds. }\end{array}$ & Hortelã miúda & Folha & $\begin{array}{l}\text { Chá, lambedor, } \\
\text { sumo }\end{array}$ & $\begin{array}{c}\text { Expectorante, } \\
\text { vermes, ameba, } \\
\text { giárdia, infecção } \\
\text { intestinal }\end{array}$ & 10 & $16,3 \%$ \\
\hline Lamiaceae & $\begin{array}{c}\text { Plectranthus } \\
\text { amboinicus (Lour.) } \\
\text { Spreng. }\end{array}$ & $\begin{array}{l}\text { Hortelã da } \\
\text { folha grossa }\end{array}$ & Folha & Lambedor, chá & $\begin{array}{c}\text { Gripe, tosse, } \\
\text { inflamação no útero }\end{array}$ & 6 & $9,8 \%$ \\
\hline Lamiaceae & $\begin{array}{c}\text { Vitex gardneriana } \\
\text { Schauer }\end{array}$ & Jaramataia & Folha & Chá, água & Doenças da próstata & 3 & - \\
\hline Lauraceae & $\begin{array}{c}\text { Persea americana } \\
\text { Mill. }\end{array}$ & Abacate & Folha & Asseio & Hemorroidas & 1 & - \\
\hline Linaceae & $\begin{array}{c}\text { Linum usitatissimum } \\
\text { L. }\end{array}$ & Linhaça & Semente & Água & $\begin{array}{c}\text { Colesterol alto, } \\
\text { imunidade baixa }\end{array}$ & 1 & - \\
\hline Lythraceae & Punica granatum L. & Romã & $\begin{array}{l}\text { Cascas do } \\
\text { caule, raiz, } \\
\text { folha }\end{array}$ & Água & $\begin{array}{c}\text { Ganganta inflamada, } \\
\text { gripe }\end{array}$ & 6 & $9,8 \%$ \\
\hline Malvaceae & $\begin{array}{c}\text { Gossypium hirsutum } \\
\text { L. }\end{array}$ & Algodão & Semente, flor & Chá, emplasto & $\begin{array}{c}\text { Febre, tumor } \\
\text { (furúnculo), intestino } \\
\text { preso }\end{array}$ & 3 & - \\
\hline Malvaceae & Sida cordifolia L. & Malva rosa & Folha & Chá & Tosse & 3 & - \\
\hline Myrtaceae & $\begin{array}{c}\text { Eucalyptus globulus } \\
\text { Labill. }\end{array}$ & Eucalipto & Folha & Chá, banho & $\begin{array}{l}\text { Gripe, febre, } \\
\text { expectorante }\end{array}$ & 6 & $9,8 \%$ \\
\hline Myrtaceae & Psidium guajava L. & Goiabeira & Flor & Chá & Diarreia & 1 & - \\
\hline Oleaceae & Olea europaea L. & Azeitona & Folha & Chá & Colesterol alto & 1 & - \\
\hline Passifloraceae & $\begin{array}{c}\text { Passiflora edulis } \\
\text { Sims }\end{array}$ & Maracujá & $\begin{array}{l}\text { Casca do } \\
\text { fruto }\end{array}$ & Pó & Diabetes, calmante & 2 & - \\
\hline Passifloraceae & $\begin{array}{l}\text { Turnera subulata } \\
\text { Sm. }\end{array}$ & Chanana & Raiz, folha & Chá, infusão & $\begin{array}{c}\text { Infecção urinária, } \\
\text { problemas na } \\
\text { próstata, inflamações }\end{array}$ & 1 & - \\
\hline Phyllanthaceae & Phyllanthus niruri L. & Quebra pedra & Raiz & Chá, água & Pedra nos rins & 6 & $9,8 \%$ \\
\hline
\end{tabular}


TABELA 3. Relação de espécies medicinais utilizadas pelas comunidades do município de picuí-pb. Convenção: ni/pi = número de indicações por planta pelos informantes.

\begin{tabular}{|c|c|c|c|c|c|c|c|}
\hline Piperaceae & Piper nigrum L. & $\begin{array}{l}\text { Pimenta do } \\
\text { reino }\end{array}$ & Folha & Chá & Febre & 1 & - \\
\hline Plantaginaceae & Plantago major L. & Tansagem & $\begin{array}{c}\text { Semente, } \\
\text { folha }\end{array}$ & Chá, sumo & $\begin{array}{c}\text { Expectorante, } \\
\text { garganta inflamada. }\end{array}$ & 4 & - \\
\hline Poaceae & $\begin{array}{c}\text { Cymbopogon citratus } \\
\text { (DC.) Stapf }\end{array}$ & Capim santo & Folha & Chá & Calmante, vermes & 6 & $9,8 \%$ \\
\hline Rutaceae & $\begin{array}{l}\text { Citrus aurantiifolia } \\
\text { (Christm.) Swingle }\end{array}$ & Limão & Folha & Chá & Gripe & 1 & - \\
\hline Rutaceae & $\begin{array}{l}\text { Citrus sinensis (L.) } \\
\text { Osbeck }\end{array}$ & Laranja & Folha & Chá & Calmante & 2 & - \\
\hline Rutaceae & Ruta graveolens L. & Arruda & Folha & Chá & $\begin{array}{l}\text { Dor de ouvido, } \\
\text { diarreia, varizes }\end{array}$ & 2 & - \\
\hline Sapotaceae & $\begin{array}{c}\text { Sideroxylon } \\
\text { obtusifolium (Humb. } \\
\text { ex Roem. \& Schult.) } \\
\text { T.D. Penn. }\end{array}$ & Quixabeira & $\begin{array}{c}\text { Casca do } \\
\text { caule }\end{array}$ & Água, banho & Inflamações & 2 & - \\
\hline Schisandraceae & $\begin{array}{c}\text { Illicium verum Hook. } \\
\text { f. }\end{array}$ & Anis & Flor & Chá & Prisão de ventre & 1 & - \\
\hline Theaceae & $\begin{array}{c}\text { Camellia sinensis } \\
\text { (L.) Kuntze }\end{array}$ & Chá preto & Folha & $\begin{array}{c}\text { Chá, infusão, } \\
\text { compressa }\end{array}$ & $\begin{array}{c}\text { Má digestão, febre, } \\
\text { dor de cabeça }\end{array}$ & 5 & $8,1 \%$ \\
\hline Verbenaceae & $\begin{array}{c}\text { Lippia alba (Mill.) } \\
\text { N.E. Br. ex Britton \& } \\
\text { P. Wilson }\end{array}$ & Erva cidreira & Folha & Chá & $\begin{array}{c}\text { Má digestão, } \\
\text { calmante, } \\
\text { hipertensão }\end{array}$ & 10 & $16,3 \%$ \\
\hline Verbenaceae & $\begin{array}{l}\text { Lippia microphylla } \\
\text { Cham. }\end{array}$ & Alecrim & $\begin{array}{c}\text { Folha, casca } \\
\text { do caule }\end{array}$ & Infusão & $\begin{array}{c}\text { Doenças do coração, } \\
\text { hipertensão, dores } \\
\text { musculares }\end{array}$ & 4 & - \\
\hline Violaceae & $\begin{array}{c}\text { Hybanthus } \\
\text { calceolaria (L.) Oken }\end{array}$ & Papaconha & Raiz & Chá & Fraqueza & 2 & - \\
\hline Xanthorrhoeaceae & $\begin{array}{c}\text { Aloe vera (L.) Burm. } \\
\mathrm{f} .\end{array}$ & Babosa & Folha & $\begin{array}{c}\text { Sumo (aplicado } \\
\text { no local), água }\end{array}$ & Câncer, ameba & 2 & - \\
\hline Ximeniaceae & $\begin{array}{l}\text { Ximenia americana } \\
\text { fo. Inermis (Aubl.) } \\
\text { Engl. }\end{array}$ & Ameixa & $\begin{array}{l}\text { Casca do } \\
\text { caule }\end{array}$ & Pó, água & $\begin{array}{l}\text { Ferimentos, } \\
\text { queimaduras }\end{array}$ & 2 & - \\
\hline Zingiberaceae & $\begin{array}{l}\text { Alpinia speciosa } \\
\text { (Blume) D. Dietr. }\end{array}$ & Colônia & Folha & Chá & Doenças do coração & 2 & - \\
\hline
\end{tabular}

que as plantas mais citadas para a fabricação de remédios não são nativas da caatinga o que pode ser uma evidência da influência de fatores externos no conhecimento etnobiológico da região.

Pelos dados apresentados podemos observar que não houve diferença significativa entre os fatores analisados nas duas áreas. Nesse sentido, podemos concluir que o conhecimento etnobotânico nas áreas urbana e rural do município é muito semelhante e que o uso de plantas medicinais ainda é bastante frequente nas comunidades estudadas.

\section{AGRADECIMENTOS}

ACAPES (Coordenação deAperfeiçoamento de Pessoal de Nível Superior), pela bolsa concedida ao primeiro autor e aos atores sociais das comunidades que participaram da pesquisa prestando valiosas informações.

\section{REFERÊNCIAS}

AGRA, M.F.; SILVA, M.G. Plantas medicinais usadas como cosméticos na Paraíba (Brasil) e na literatura. Revista Brasileira de Farmácia, v.72, n.2, p.42-44, 1993.

ALBUQUERQUE, U.P.; LUCENA, R.F.P. Métodos e técnicas de pesquisa etnobotânica. 1.ed. Recife: Livro Rápido/NUPEEA, 2004. 189p.

ALMEIDA, N.F.L.; et al., Levantamento etnobotânico de 
plantas medicinais na cidade de Viçosa, MG. Revista Brasileira de Farmácia, v.90, n.4, p.316-320, 2009.

AMOROZO, M.C.M.; GELY, A. Uso de plantas medicinais por cablocos do baixo amazonas, Barcarena-PA, Brasil. Boletim Museu Paranaense Emilio Goeldi, v.4, n.1, p.47-131, 1988.

BAILEY, K. Methods of social reserch. 4th ed. New York: The Free Press, 1994. 588p.

BENNETT, B.C.; PRANCE, G.T. Introduced plants in the indigenous pharmacopeia of Northern South America. Economic Botany, v.54, n.1, p. 90-102, 2000.

DA SILVA, C.G. Estudo etnobotânico e da atividade antimicrobiana 'in vitro' de plantas medicinais na comunidade do Sítio Nazaré, município de Milagres, Ceará. 2012. 93p. Dissertação (Mestrado em Ciências Florestais) - Universidade Federal de Campina Grande, Patos-PB.

DA SILVA, C.S.P. As plantas medicinais no município de Ouro Verde de Goiás, GO, Brasil: uma abordagem etnobotânica. 2007. 153p. Dissertação (Mestrado em Botânica) - Universidade de Brasília, Brasília-DF.

FRANCISCO, P.R.M.; et al., Zoneamento de Risco Climático e Aptidão de Cultivo para o Município de Picuí - PB. Revista Brasileira de Geografia Física, v.5, p.1043-1055, 2011.

GARIGLIO, M.A.; et al. Uso sustentável e conservação dos recursos florestais da caatinga. 1.ed. Brasília/DF: Serviço Florestal Brasileiro, 2010.368p.

INSTITUTO BRASILEIRO DE GEOGRAFIA E ESTATÍSTICA (IBGE). IBGE Cidades. 2010. Disponível em: <http://cidades.ibge.gov.br/xtras/perfil.php?lang= \&codmun=251140\&search=paraiba|picui|infograficos:informacoes-completas>. Acesso em: 19 maio 2011.

MASSAROTO, N.P. Diversidade e uso de plantas medicinais por comunidades quilombolas kalunga e urbanas no Nordeste do Estado de Goiás-GO, Brasil. 2009. 130p. Dissertação (Mestrado em Ciências Florestais) - Universidade de Brasília, Brasília-DF.

MARINHO, M.G.V. Levantamento de plantas medicinais em duas comunidades do Sertão Paraibano, Nordeste do Brasil, com ênfase na atividade Imunológica de Amburana cearensis (Fr. All.) A.C. Smith (Fabaceae). 2006.171p. Tese (Doutorado em Produtos Naturais e Sintéticos Bioativos) - Universidade Federal da Paraíba, João Pessoa-PB.

PALMER, C.T. The inclusion of recently introduced plants in the Hawaiian ethnopharmacopeia. Economic Botany, v.58, n.1, p.280-293, 2004.

PRANCE, G.T.; BALEE, W.; BOOM, B.M.; CARNEIRO, R.L. Quantitative ethnobotany and the case for conservation in Amazônia. Conservation Biology, v.1, p.296-310, 1987.

RODAL, M.J.N.; SAMPAIO, E.V.S.B.; FIGUEIREDO, M.A. Manual sobre métodos de estudo florístico e fitossociológico - ecossistema caatinga. 1.ed. Brasília: Sociedade Botânica do Brasil/Seção Regional de Pernambuco, 1992. 32p.

SOUZA, C.D.; FELFILI, J.M. Uso de plantas medicinais na região de Alto Paraíso de Goiás, GO, Brasil. Acta Botânica Brasílica, v.20, n.1, p.135-142, 2006. 